This item was submitted to Loughborough's Research Repository by the author.

Items in Figshare are protected by copyright, with all rights reserved, unless otherwise indicated.

\title{
What are the behaviours and attitudes of staff that make their students use Lecture Capture more?
}

PLEASE CITE THE PUBLISHED VERSION

http://dx.doi.org/10.21125/iceri.2016.1514

PUBLISHER

IATED

VERSION

NA (Not Applicable or Unknown)

\section{PUBLISHER STATEMENT}

This work is made available according to the conditions of the Creative Commons Attribution-NonCommercialNoDerivatives 4.0 International (CC BY-NC-ND 4.0) licence. Full details of this licence are available at: https://creativecommons.org/licenses/by-nc-nd/4.0/

\section{LICENCE}

CC BY-NC-ND 4.0

\section{REPOSITORY RECORD}

King, Melanie R.N., Ray Dawson, Steve Rothberg, and Firat Batmaz. 2019. "What Are the Behaviours and Attitudes of Staff That Make Their Students Use Lecture Capture More?". figshare. https://hdl.handle.net/2134/24811. 


\title{
WHAT ARE THE BEHAVIOURS AND ATTITUDES OF STAFF THAT MAKE THEIR STUDENTS USE LECTURE CAPTURE MORE?
}

\author{
M. King ${ }^{1}$, R. Dawson ${ }^{2}$, F. Batmaz ${ }^{2}$, S. Rothberg ${ }^{3}$ \\ ${ }^{1}$ IT Services, Loughborough University (UNITED KINGDOM) \\ ${ }^{2}$ Department of Computer Science, Loughborough University (UNITED KINGDOM) \\ ${ }^{2}$ School of Mechanical, Electrical and Manufacturing Engineering, Loughborough University \\ (UNITED KINGDOM)
}

\begin{abstract}
This paper outlines a realist evaluation of the Lecture Capture (LC) initiative at a top 10 University in the UK, for the academic year 2014/15. LC (sometimes referred to as Web Based Lecture Technologies in the literature) is an umbrella term used to describe the capturing of lecture content (video, audio and slides) and is a suite of technologies that include hardware, server software and systems, desktop applications and audio-visual devices.

The evaluation utilised a full set of engagement analytics of LC usage and attendance data across a whole institution for an entire academic year. It also adopted a realist approach to theory building and testing using both implementation data and qualitative data from staff and students. The study involved four cycles of increasingly focused evaluation enquiry in order to illicit what works (and does not work), for whom, in which contexts and the reasons why.

The investigation found that positive viewing outcomes were linked to particular staff attitudes and behaviours and not to specific disciplines, course content, departments or previous experience of using LC. The objective of this paper is to describe the methodology, approach and detailed findings for this part of the investigation. It then uses this evidence, in the context of the literature, to make recommendations on future policy and intervention design to support greater utilisation of captured lectures.

These findings include, that staff users, who have consistently high completion and cohort viewing rate across all of their courses, are more likely to come from departments where LC use by staff is firmly embedded in practice or are the first to use LC in their department. These staff are very experienced teachers, who were influenced by students to use LC and continue to use it because of positive feedback from their students. They pro-actively tell their students that the lectures are available online, with instructions on how to access them and regularly check the viewing figures.

Ultimately, staff need to perceive the benefits themselves of using this technology and reflect on their own goals in its use. Gathering feedback from students will help to galvanize their personal opinion on the predominant usefulness of the technology for their discipline, their cohort and their pedagogical style and personal development.
\end{abstract}

Keywords: Lecture capture, realist evaluation, behaviour, attitudes, educational technology.

\section{INTRODUCTION}

Lecture Capture (sometimes referred to as Web Based Lecture Technologies in the literature) is an umbrella term used to describe the capturing of live lecture content (video, audio and slides) and is a suite of technologies that include hardware, server software and systems, desktop applications and audio-visual devices. In the summer of 2015 a 6-month evaluation commenced of a UK University's Lecture Capture (LC) initiative. There were a number of reasons why a thorough evaluation at this time was necessary and the choice of an appropriate evaluative approach important. LC itself had a number of proactive and vocal proponents, however, there were also many staff who were unconvinced of the technology, mirroring the growing scholarly critique surfacing the distrust of educational technology in general [1]. Therefore, the objective of the evaluation was to gather a rigorous evidence base combining analytics and theory to explain findings, with the aim of further developing the strategy and LC policy based on its current use and future potential.

Many years earlier, the practice of capturing live lectures, using video or LC technologies, had been slowly introduced into teaching practice by a small group of evangelists on a new history programme 
and also on a distance learning programme in engineering. Since then, its use has grown organically and was adopted by new staff on an ad-hoc basis having heard of it mainly by word of mouth. It was then subsequently promoted at LC events, organised by a group of early adopters (from a variety of departments) acting as LC mentors.

There had also been, in more recent years, a growing pressure from the student body for widespread utilisation of technologies to aid the capturing and replay of live lectures. A greater uptake of the LC facility by staff was therefore one of the Student Union's top ten priorities in 2015, which provided a catalyst for an agreement on the University's position on the use of LC. A literature review was undertaken, highlighting the pedagogic benefits, fed into the creation of a new university-wide policy on the use of LC across all disciplines. There was also a need, at that time, to provide a renewed case for further investment to equip a greater number of lecture theatres with the technologies to aid wide-spread use. Therefore, ongoing evaluation was needed to justify further investment and see whether the new university policy had led to an increased uptake by staff.

Six months later, the time was right for the collection and analysis of evidence to help answer some of the following questions. Does the policy provide a catalyst for greater adoption by staff? What might be the tipping point in wide-scale acceptance of this technology by staff? What more could be done to improve uptake and support embedding of the technologies in every day teaching and learning? What type of evidence might demonstrate to students that there had indeed been greater uptake that was providing pedagogic benefits for students?

The objectives of this paper are to provide a general summary of the overall evaluation methodology, including an outline of the 4 cycles of iterative research. Then, describe in detail one of these cycles, which was an in-depth survey of staff users. These were the 16 users who, in particular, had consistently high rates of students viewing and amount of content viewed, across all of their courses and were hypothesised to have particular behaviours and attitudes that led to their students utilising the captures of their lectures more than those in other modules. This paper provides a detailed insight in the process and findings of this particular part of the evaluation and uses this evidence, in the context of the literature, to make recommendations on future policy and intervention design to support greater utilisation of captured lectures.

\section{EVALUATION METHODOLOGY AND EARLY FINDINGS}

\subsection{Overall evaluation methodology}

Realist evaluation [2] is a theory-based evaluation methodology and was chosen for a number of reasons. A realist approach assumes that nothing works everywhere for everyone and that context really does make a difference. It is a way of thinking that adopts the philosophy of scientific realism [3] to unearth evidence of distinct positive and negative outcomes as consequences of underlying programme mechanisms (i.e. participants' reactions to the mixture of resources provided) within particular contexts. Contexts for example might be particular types of people, institutional settings or even the wider social, political, economic and cultural setting of the programme. Therefore, it was determined that realist evaluation was an appropriate approach to take because the LC has had ad hoc usage at department level that, anecdotally, seems to work for some. However, real evidence of what is working, for whom, in what circumstances and why still needs to be understood.

The methodology has been further refined [4] into a framework that supports the mapping of complex learning technology implementations and associated embedding activities. For example, the refined framework includes architectural reference models to help categorise particular technical contexts and actors in educational settings, therefore helping to describe 'contexts' in a standard way across department settings to aid analysis and synthesis.

\subsubsection{Evidence collection that supports theory building and testing}

Realist evaluation begins by clarifying the 'programme theory' and the mechanisms $(\mathrm{m})$ that are likely to operate (e.g. change in beliefs, desires and behaviour), the contexts (c) within which they operate and outcomes (o) that can be observed. The initial idea, the goal, the expectation, hypothesis or 'programme theory' is that if certain resources (whether material, social or cognitive) are provided then they will edge into a subject's reasoning, generating a change in thought or behaviour. These theories (hypotheses) provide a realist evaluation with its starting point, the programme theory, being the unit of analysis rather than the programme itself. These theories are generated and evidence is then 
collected in the form of context $(c)+$ mechanism $(m)=$ outcome (o) configurations in sentence-like configurations $\mathrm{C}+\mathrm{M}=\mathrm{O}$ called $\mathrm{CMOCs}$ (pronounced seemocs) in the realist literature. These are then analysed and form a starting point of, 'the intervention theory works under conditions $\mathrm{X}, \mathrm{Y}$ and $\mathrm{Z}$ ' as an if-then proposition [5].

\subsection{The Lecture Capture programme policy and programme theory}

The original University's 2014/15 LC Policy mostly comprised guidelines for staff on their use of LC. It articulates the institution's strategic approach to LC which strongly encourages the use of LC. It also addresses the perceived barriers, for example, intellectual property and copyright, and provides a list of guidelines and information relating to technical support. It was intended that this policy would be communicated by the most senior member of teaching staff within each school.

An initial hypothesis, or 'programme theory' as realist researchers refer to it, was generated based on the assumption underlying the institutional LC policy (i.e. the reason why it was expected to work). The theory being, that establishing an institutional policy on LC (c) that is communicated by senior staff, (c) will encourage more staff to use LC $(\mathrm{m})$ and should allay concerns perceived as barriers to adoption $(\mathrm{m})$. The outcome being that a tipping point, or critical mass of users, will speed up adoption by more staff (o) and the pedagogic benefits will impact on a greater number of students (o). This programme theory then provided the investigation with its starting point.

\subsection{Context and outcome mapping: an iterative approach to theory building}

A preliminary mapping of the initiative helped to identify the components of the technological context, detailed usage statistics and the key people involved at different stages of the LC implementation. Four cycles of investigation then commenced that sought to gather evidence to support or disprove the initial programme theory. Within each iteration, activities included: gathering increasingly targeted data on specific contexts and outcomes; adding detail to the initial mapping of the LC implementation and embedding activities; generating and refining programme theories to determine what works, in which contexts, for whom and why.

Cycle 1 commenced by establishing the viewing outcomes relating to the contexts of 'department' and 'prevalence' of local champions. Cycle 2 then looked specifically at 'lecturer' contexts and mechanisms linked to positive viewing outcomes. Cycle 3 looked at whether the context of particular 'timetable' slots were linked to positive viewing outcomes and whether this had any relationship with patterns of attendance. Finally, cycle 4 looked at 'student' contexts and mechanisms linked to negative viewing outcomes.

\subsection{Early findings}

During the academic year 2014/15, a total of 275 courses or events were captured as relating to modules or programmes, the majority being split between undergraduate first year $(22 \%)$, second year $(26 \%)$, third year $(19 \%)$ and postgraduate $(23 \%)$. The remaining $10 \%$ covered foundation, placement or fourth year undergraduate teaching modules. A total of 2566 captures were created within those 275 courses amounting to 134 days, 20 hours and 17 minutes of content.

From mapping staff uptake, it was found that there were indeed more staff users in departments where the most senior member of teaching staff were users themselves and these staff were actively advocating the university's LC policy. However, the expected policy outcome - that there would be a corresponding uptake by students of the captured lectures - was not evidenced. In fact, the overall viewing figures were lower than expected and an increase in viewing habits did not correlate with departments that had a higher number of staff users. For example, for captured sessions that were between 30 and 80 minutes long (1194), the average amount of content watched per capture was $43 \%$, the most common pattern of viewing was $25-30$ minutes of each capture by $0-5 \%$ of the associated cohort of students. For captured sessions that were longer than 80 minutes (871), the average amount watched dropped to $31 \%$ of the content with the most common pattern of viewing of $35-40$ minutes of the capture by $5-10 \%$ of the associated cohort. These averages varied wildly across departments and within departments. Some courses for example, having very positive viewing outcomes, therefore bringing up the mean for that department.

The investigation, then sought to unearth the particular contexts that had higher viewing outcomes (a high rate of content watched by a large proportion of the cohort). As a starting point, theories were generated based on the LC literature, for example; that viewing differs according to the stage students 
are at in their degree journey [6]; certain types of teaching approach or content type make a difference [7]; or perhaps an increase in usage occurs when additional materials are provided online to accompany the LC [8].

After significant analysis, it was found that although first years were the least engaged with lecture capture, positive viewing outcomes did not appear particularly linked to stage of study, department, course, or timetable slot but to certain members of staff from across the University. The investigation then sought to collect evidence to understand why this might be.

\section{THE SURVEY}

Out of 143 staff users, there were 16 who had a significantly higher than average number of cohort viewers and a completion rate above their own department's average across all of the courses they delivered ( 20 courses in total: 6 business and economics, 9 science and engineering, 5 social sciences). These staff were spread across 12 departments with a variety of ages and academic rank. 4 were from a department that had the senior member of teaching staff acting as a technology evangelist' and pro-active user of LC and 4 were from the department that first adopted LC in 2009. Indicating that these staff were clustered in the departments where LC was firmly established. All of these staff had English as a first language.

\subsection{Survey methodology}

At its core, the LC initiative is a behaviour change intervention, that is, it sets out to change the behaviour of staff to utilise the facility to capture their lectures and potentially adapt and enhance their pedagogy. The Behaviour Change Wheel [9] is a useful tool for designing and classifying behaviour change interventions developed from 19 frameworks of behaviour change. The tool differentiates between the main function of an intervention (i.e. a youth club for teenagers with Asperger's will have a function of 'enablement') and provides different policy categories (i.e. a policy of 'communication/marketing' with local schools) and a model for describing different types of 'target' behaviours, within Capability, Opportunity and Motivation (i.e. the intervention provides a social 'opportunity' to change behaviours, by allowing teenagers to get out and build a friendship network). Our evaluation used this tool to classify the LC initiative, with an intervention function of 'persuasion', with a policy category of 'guidelines' and target behaviours for staff classified as 'psychological capability', 'social opportunity' and 'reflective motivation'.

It did in fact appear that individuals may have had particular attributes, attitudes, behaviours or teaching approaches that resulted in an increased use of LC. Was this as a result of the policy or resources provided to them by the LC initiative, or was it related to individual skills, capabilities, opportunities or intrinsic or extrinsic motivation? It was felt that an anonymous online survey could be used for these 16 staff (who had a significantly higher than average number of cohort viewers and a completion rate above their own department's average) to collect data to refine or refute a number of initial candidate theories.

\subsubsection{Candidate theories}

To theorize potential contexts and mechanisms of staff with highly viewed LC, middle range theories were generated from two existing behavioural theories. Azjen's theory of planned behaviour [10] was used to generate the following hypothesis: Staff who feel that LC provision is a desirable norm for students (c) and believe in their own ability and ease-of-access to utilise the technologies provided $(\mathrm{m})$ would consistently capture of all of their courses (o). Schon's reflective practitioner theory [11] was used to generate the following hypothesis: staff who frequently reflect on their own practice (c) and are keen to incorporate the LC technology into new ways of teaching (e.g. flipped lectures [12]) (m) would result in a necessity for their students to view their sessions due to their chosen pedagogic approach.

\subsection{Survey questions}

As part of the Behaviour Change Wheel [9], The COM-B behavioural model (that predicts that Capability + Opportunity + Motivation will result a change in Behaviour) was used as a conceptual platform to understand and categorise staff behaviours. However, in order to elicit a more detailed understanding, the evaluators used the Theoretical Domains Framework (TDF), which has been developed and validated [13] within implementation research, to support evidence-based behaviour change interventions. In order to collect and analyse the survey data to specifically support or refute 
the candidate hypothesis, Table 1 shows how the TDF domain was mapped onto the COM-B categories and then survey questions generated within each.

\begin{tabular}{|c|c|c|}
\hline \multicolumn{3}{|c|}{$\begin{array}{l}\text { Table 1. Survey questions based on the COM-B behavioural model and } \\
\text { Theoretical Domains Framework (TDF) }\end{array}$} \\
\hline COM-B category & TDF domain & Questionnaire item \\
\hline $\begin{array}{l}\text { Psychological } \\
\text { Capability }\end{array}$ & Knowledge & 1. How long have you been teaching? \\
\hline $\begin{array}{l}\text { Psychological } \\
\text { Capability }\end{array}$ & Skills & 6. How confident a user are you of the lecture capture technology? \\
\hline $\begin{array}{l}\text { Psychological } \\
\text { Capability }\end{array}$ & $\begin{array}{l}\text { Behavioural } \\
\text { regulation }\end{array}$ & $\begin{array}{l}\text { 15. Do you look at the viewing statistics for your lectures and take } \\
\text { action based on the figures e.g. encourage more viewing? }\end{array}$ \\
\hline $\begin{array}{l}\text { Physical } \\
\text { opportunity }\end{array}$ & $\begin{array}{l}\text { Environmental } \\
\text { context }\end{array}$ & $\begin{array}{l}\text { 2. Do you hold any department roles relating to teaching? } \\
\text { 9. Have you consulted any of the following resources or taken part in } \\
\text { any lecture capture events? } \\
\text { 10. Have you ever sought pedagogic advice about your use of lecture } \\
\text { capture material in your teaching? } \\
\text { 12. Did you have to change any element of your existing teaching } \\
\text { practice or material to accommodate the capturing of your lectures? }\end{array}$ \\
\hline Social opportunity & $\begin{array}{l}\text { Social } \\
\text { influences }\end{array}$ & $\begin{array}{l}\text { 8. Did anyone in particular influence your decision to use it? } \\
\text { 16. How vocal are your own students in their desire to have their } \\
\text { lectures recorded? }\end{array}$ \\
\hline $\begin{array}{l}\text { Reflective } \\
\text { Motivation }\end{array}$ & $\begin{array}{l}\text { Professional } \\
\text { Identity }\end{array}$ & $\begin{array}{l}\text { 3. Do you have a UK HEA (Higher Education Academy) Professional } \\
\text { accreditation? } \\
\text { 17. Do you consider yourself a champion of the University's lecture } \\
\text { capture initiative? }\end{array}$ \\
\hline $\begin{array}{l}\text { Reflective } \\
\text { Motivation }\end{array}$ & $\begin{array}{l}\text { Beliefs about } \\
\text { capabilities }\end{array}$ & $\begin{array}{l}\text { 4. Are you a recipient of a 'Research informed teaching award' or } \\
\text { 'Teaching Innovation Award?' }\end{array}$ \\
\hline $\begin{array}{l}\text { Reflective } \\
\text { Motivation }\end{array}$ & Intentions & $\begin{array}{l}\text { 9. Have you consulted any of the following resources or taken part in } \\
\text { any lecture capture events? } \\
\text { 10. Have you ever sought pedagogic advice about your use of lecture } \\
\text { capture material in your teaching? } \\
\text { 11. Are you selective about what you capture or do you capture } \\
\text { everything? } \\
\text { 13. Have you used the subsequent captures to review your own } \\
\text { teaching style/methods/pedagogy and make changes? } \\
\text { 14. Do you promote the capture material to your students and if so, } \\
\text { what do you tell them? }\end{array}$ \\
\hline $\begin{array}{l}\text { Reflective } \\
\text { Motivation }\end{array}$ & Goals & 7. What was your motivation for using lecture capture? \\
\hline $\begin{array}{l}\text { Reflective } \\
\text { Motivation }\end{array}$ & $\begin{array}{l}\text { Beliefs about } \\
\text { consequences }\end{array}$ & $\begin{array}{l}\text { 18. You are one of } 16 \text { members of staff with a significantly higher } \\
\text { than average \% of cohort viewers. Why do you think that is? } \\
\text { 19. What additions to the Loughborough lecture capture policy, or } \\
\text { initiative as a whole, do you believe would help to encourage more } \\
\text { students to engage with the captured recording of sessions? }\end{array}$ \\
\hline $\begin{array}{l}\text { Automatic } \\
\text { motivation }\end{array}$ & Reinforcement & 5. How many years have you been using lecture capture? \\
\hline
\end{tabular}

\subsection{Survey findings}

15 out of the 16 staff responded (94\%) and Table 2 shows the refined theories for positive viewing outcomes in relation to a particular lecturer, linked to the evidence collected about specific contexts and mechanisms. These theories were generated by analysing survey responses and provide us with the reasons why certain lecturers had greater utilisation of their lecture captures. 
Table 2: Refined theories for 'lecturer' contexts and mechanisms linked to positive viewing outcomes

\section{CONTEXT}

Very experienced teachers $\left(C^{1}\right)$ with no professional status, teaching role or teaching award $\left(C^{2}\right)$.

Very experienced teachers $\left(C^{1}\right)$ with professional status $\left(C^{3}\right)$ and department teaching role $\left(\mathrm{C}^{4}\right)$.

A few vocal students who have expressed how valuable $L C$ is $\left(C^{5}\right)$.

Have been using LC for 1 year $\left(C^{6}\right)$.

Have been using LC for $2-6$ years $\left(C^{7}\right)$.

Have personally reviewed their own LC content $\left(C^{8}\right)$ and viewing figures $\left(C^{9}\right)$.

Regularly tell students that lectures are available on Review and how to find them $\left(\mathrm{C}^{10}\right)$.

\section{+ MECHANISM}

Thought that LC was the desirable norm $\left(\mathrm{M}^{1}\right)$, was popular with students $\left(\mathrm{M}^{2}\right)$ and involved little effort on their part $\left(\mathrm{M}^{3}\right)$.

Were influenced by student requests $\left(\mathrm{M}^{4}\right)$, and own desire to improve course for variety of nonstandard situations (DL, language, placement interviews) $\left(\mathrm{M}^{5}\right)$.

Have reinforced opinions on the benefits of $L C\left(M^{6}\right)$.

Have not felt the need to consult support resources or ask for pedagogical advice $\left(\mathrm{M}^{7}\right)$.

Have not felt the need to seek pedagogic advice but have looked for technical help as required from system documentation $\left(\mathrm{M}^{8}\right)$.

To work on the aspects of teaching style and revise lecture content $\left(\mathrm{M}^{9}\right)$ and to ensure students are watching $\left(\mathrm{M}^{10}\right)$.

Desire to promote LC to students, particularly those who find lecture content technical or difficult to follow $\left(\mathrm{M}^{11}\right)$.

\section{= OUTCOME}

Captured all sessions across all modules with little change to teaching practice $\left(\mathrm{O}^{1}\right)$ and received positive viewing outcomes $\left(\mathrm{O}^{2}\right)$.

Captured all sessions across all modules with little change to teaching practice $\left(\mathrm{O}^{1}\right)$ and received positive viewing outcomes $\left(\mathrm{O}^{2}\right)$.

Have the intention to continue with $\operatorname{LC}\left(\mathrm{O}^{3}\right)$.

Have some doubts about expertise $\left(\mathrm{O}^{4}\right)$.

Are confident or extremely confident in personal expertise with $\mathrm{LC}\left(\mathrm{O}^{5}\right)$.

Alterations and enhancements to pedagogy $\left(\mathrm{O}^{6}\right)$ as well as positive viewing outcomes $\left(\mathrm{O}^{2}\right)$.

Positive viewing outcomes, particularly for content that is hard to understand first time $\left(\mathrm{O}^{2}\right)$.

All of the respondents are very experienced teachers, many of whom were influenced by students to use LC and continue to use it because of positive feedback from their students. They pro-actively tell their students that the lectures are available online, with instructions on how to access them and regularly check the viewing figures. Although most do not feel the need to seek pedagogic advice or support, the more experienced users are those who tend to seek technical support from online resources and are more confident about their expertise. They report a motivation to provide their students with the additional LC resource for catch up on technical content or when sessions are missed. Barriers to use are low as there has been little change to their pedagogy and minimal effort on their part to adopt the technology. A few of these staff do report using the captures to review their own teaching, however, and review their content or delivery as a consequence. None of the respondents were using LC for flipped lectures [12].

Further investigation would be required to find underlying student mechanisms connected with greater use of LC content for these particular courses. Some responses also indicate that either a perceived or actual drop in attendance has been noted or that perhaps more students are viewing because they have a bad slot (e.g. late on a Friday) in the timetable. Other possible reason for high viewing figures, given by respondents, was the technical nature of their module. However, many were also surprised at the high viewing outcome for their modules as they were concerned about the quality of the captures (e.g. those using visualizers in class which is not picked up on that particular LC installation).

\section{CONCLUSIONS}

\subsection{Survey Summary}

Our survey evidence supports previous studies [14] [15], who also found that lecturers' cite the reasons for using LC are because they believe that students expect them to and to accommodate students who cannot attend lectures in person for valid reasons. A recent review of the LC literature (covering institutional, student and lecturer issues) recommended that future research should address 
the need for using large, demographically represented lecturers with links to learning theories to explain findings [16]. This paper therefore contributes to this required research direction.

Results from the survey also reveal new findings. That is staff who have high viewing figures for their captured sessions share many similar attributes such as; teaching experience and technical capability; attitudes towards their teaching practice; and demonstrate many behaviours and attitudes that provide evidence of strong individual reflective motivation. For example, they are more likely to be influenced by student requests and feedback on their use of LC rather than being influenced by a colleague. Azjen's theory of planned behaviour [10] can be seen to explain many of the programme theories (Table 2) elicited. Schon's reflective practitioner theory [11] also provides a framework of understanding for many of the common contexts and mechanisms uncovered in the responses of these staff.

\subsection{Recommendations on future policy and LC implementation}

The existing LC intervention had been classified, using the Behaviour Change Wheel [9], as having a function of 'persuasion', with a policy category of 'guidelines' and target behaviours of staff classified as 'psychological capability', 'social opportunity' and 'reflective motivation'. If the intervention was refined to support the specific target behaviours, as demonstrated by the staff having positive viewing outcomes, then more emphasis should be placed on enabling individual reflective motivation. For example, as well as providing online software documentation to support enhanced technical capability, staff should also be provided with the tactics to adopt that will ensure positive student engagement and be encouraged to evaluate and monitor this for themselves. For example, advocating the benefits and use of LC, particularly in Semester 1 (where overall viewing figures were lower than Semester 2) and also providing staff with resources to hand out to students, that help communicate the pitfalls of habitual catch-up.

Previous research has found that the adoption of new technology requires teachers to perceive the benefits in its use [17] and our survey supports this. Ultimately, staff need to perceive the benefits and also reflect on their own goals in its use. Gathering feedback from students will help to galvanize their personal opinion on the predominant usefulness of the technology for their discipline, their cohort and their pedagogical style and personal development. With this in mind, an intervention function of 'education' rather than 'persuasion' might be more appropriate with policy guidelines encouraging individual practitioners' reflective processes. It is important to also note that the LC initiative should also be designed with students in mind and therefore more consideration should be given to refining policies and practices with a view to changing students' perceptions and behaviour too.

\section{REFERENCES}

[1] N. Selwyn, Distrusting educational technology: critical questions for changing times, Routledge, 2014.

[2] R. Pawson, The Science of Evaluation - A Reaslist Manifesto, London: Sage, 2013.

[3] R. Bhaskar, A Realist Theory of Science, London: Routledge, 1978.

[4] M. R. N. King, S. R. Rothberg, R. Dawson and F. Batmaz, "Bridging the edtech evidence gap: A realist evaluation framework refined for complex technology initiatives," Journal of Systems and Information Technology, vol. 18, no. 1, p. XX, 2016.

[5] R. Pawson and S. Sridharan, "Theory-driven evaluation of public health programmes," in Evidence Based Public Health, Oxford, Oxford University Press, 2010.

[6] M. A. Drouin, "If You Record It, Some Won't Come Using Lecture Capture in Introductory Psychology," Teaching of Psychology, vol. 41, no. 1, pp. 11-19, January 2014.

[7] J. Danielson, V. Preast, H. Bender and L. Hassall, "Is the effectiveness of lecture capture related to teaching approach or content type?," Computers and Education, vol. 72, pp. 121-131, March 2014.

[8] S. Moes and C. Young, "Which types of lecture capture, knowledge and instruction clips could improve the quality of learning outcomes?," in ICERI2013 Proceedings: 6th International Conference of Education, Research and Innovation, Seville, 2013. 
[9] S. Michie, L. Atkins and R. West, The Behaviour Change Wheel - A Guide to Designing Interventions, UK: Silverback publishing, 2014.

[10] I. Ajzen, "Theory of Planned Behaviour," in The Handbook of Theories of Social Psychology, vol. 1, P. A. M. Van Lange, A. W. Kruglanski and E. T. Higgins, Eds., London, Sage, 2012, pp. 438-459.

[11] D. Schon, Educating the Reflective Practitioner, San Francisco: Josey-Bass, 1987.

[12] Educause Learning Initiative, "Flipped Classrooms", February 2012. [Online]. Available: https://net.educause.edu/ir/library/pdf/eli7081.pdf [Accessed 7 October 2016].

[13] J. Cane, D. O'Connor and S. Michie, "Validation of the theoretical domains framework for use in behaviour change and implementation research," Implementation Science, vol. 7, no. 37, 2012.

[14] S. Chang, "Academic perceptions of the use of Lectopia: A University of Melbourne example," in ICT: Providing choices for learners and learning, Singapore, 2007.

[15] M. Gosper, D. Green, M. McNeill, R. Phillips, G. Preston and K. Woo, "The impact of webbased lecture technologies on current and future practices in learning and teaching," April 2008. [Online]. Available: http://www.cpd.mq.edu.au/teaching/wblt/overview.htm. [Accessed 20 September 2016].

[16] F. V. O'Callaghan, D. L. Neumann, L. Jones and P. A. Creed, "The use of lecture recordings in higher education: A review of institutional, student and lecturer issues," Education and Information Technologies, December 2015.

[17] W. Sugar, F. Crawley and B. Fine, "Examining teachers' decisions to adopt new technology," Educational Technology and Society, vol. 7, pp. 201-213, 2004. 